\title{
Evaluation of lipid profile and its relationship with blood pressure in patients with Cushing's disease
}

\author{
Lang Qin', *, Xiaoming Zhu', *, Xiaoxia Liu' ${ }^{1}$, Meifang Zeng ${ }^{1}$, Ran Tao', Yan Zhuang ${ }^{1}$, Yiting Zhou ${ }^{1}$, \\ Zhaoyun Zhang ${ }^{1,3}$, Yehong Yang ${ }^{1}$, Yiming Li ${ }^{1}$, Yongfei Wang ${ }^{2,3}$ and Hongying Ye ${ }^{1}$ \\ ${ }^{1}$ Division of Endocrinology and Metabolism, Huashan Hospital, Shanghai Medical College, Fudan University, Shanghai, China \\ 2Division of Neurosurgery, Huashan Hospital, Shanghai Medical College, Fudan University, Shanghai, China \\ ${ }^{3}$ Shanghai Pituitary Tumor Center, Shanghai, China \\ Correspondence should be addressed to Y Wang or H Ye: eamns@hotmail.com or yehongying@huashan.org.cn \\ *(L Qin and X Zhu contributed equally to this work)
}

\begin{abstract}
Introduction: The purpose of the study was to describe lipid profile and explore pathogenetic role of LDL-c on hypertension in patients with Cushing's disease (CD). Hypertension is a common feature in patients with CD. Previous study found low-density lipoprotein cholesterol (LDL-c) uptake in vascular cells might be involved in vascular remodeling in patients with $C D$. Therefore, we evaluated the relationship between lipid profile and the blood pressure in patients with $C D$.

Methods: This retrospective study included 84 patients referred to Huashan Hospital for the evaluation and diagnosis of CD from January 2012 to December 2013. All subjects had detailed clinical evaluation by the same group of endocrinology specialists to avoid subjective influences.

Results: We found that high LDL-c patients had significant higher body mass index (BMI), systolic blood pressure (SBP), cholesterol (CHO), triglyceride (TG), and apolipoproteinB $($ apoB) $(P<0.05)$. An association was detected between SBP values and lipids profile including $\mathrm{CHO}$, TG, LDL-C, apolipoproteinA (apoA), apoB and lipoprotein(a) (LP(a)). After adjustment for all covariates, the LDL-c remained positively associated with SBP. In patients with or without taking statins, patients with $L D L-c \geq 3.37 \mathrm{mmol} / \mathrm{L}$ had higher SBP than patients with LDL-c $<3.37 \mathrm{mmol} / \mathrm{L}$. Then, LDL-c was coded using restricted cubic splines (RCS) function with three knots located at the 5th, 50th and 95th percentiles of the distribution of LDL-C. Compared to individuals with $3.215 \mathrm{mmol} / \mathrm{L}$ of LDL-C, individuals with 4.0, 4.5 and $5.0 \mathrm{mmol} / \mathrm{L}$ of LDL-c had differences of $3.86,8.53$ and $14.11 \mathrm{mmHg}$ in SBP, respectively.

Conclusions: An independent association between LDL-C and SBP was found in patients with CD. We speculate that LDL-c may be a pathogenic factor for hypertension in those patients.
\end{abstract}

\author{
Key Words \\ adrenal \\ - $\mathrm{CD}$ \\ - metabolism \\ - lipid profile \\ - blood pressure
}

Endocrine Connections (2018) 7, 637-644

\section{Introduction}

Hypertension is a common chronic condition in patients with Cushing's disease (CD) and may be the first sign (1).
The pathogenesis of glucocorticoid-induced hypertension is not fully understood. It is thought to be related in part

$$
\begin{array}{lr}
\text { http://www.endocrineconnections.org } & \text { O2018 The authors } \\
\text { https://doi.org/10.1530/EC-18-0010 } & \text { Published by Bioscientifica Ltd }
\end{array}
$$

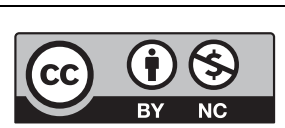

This work is licensed under a Creative Commons Attribution-NonCommercial 4.0 International License. 
to a state of mineralocorticoid excess as well as effects of cortisol on the peripheral vasculature. Exposure to excess cortisol can lead to increased cardiac output and increased peripheral and renovascular resistance (2). Chronic hypertension places patients at an increased risk for cardiovascular morbidity.

Glucocorticoids cause hypertension through several mechanisms (3): mineralocorticoid activity of cortisol; activation of the renin-angiotensin system (RAS); enhancement of cardiovascular reactivity to vasoconstrictors (catecholamines, vasopressin and angiotensin 2); increased adrenergic receptor sensitivity to catecholamines; suppression of the vasodilatory systems (NO synthase, prostacyclin and kinin-kallikrein); increased cardiac output, total peripheral resistance and renovascular resistance; insulin resistance and sleep apnea.

In adult patients with Cushing's syndrome (CS), hypertension is present in $70-85 \%$ of patients; after surgical treatment, approximately $30 \%$ of adults have persistent hypertension (2). Lodish found that blood pressure in pediatric patients with CS was positively correlated with urinary free cortisol (UFC) and midnight cortisol before operation (4).

Despite the decrease in blood pressure values after surgical cure, a portion of patients remained hypertensive 1 year after operation. These previous data suggest that residual hypertension in patients with CS may be due in part to vascular remodeling (5).

Large artery stiffening in patients with isolated systolic hypertension (ISH) may relate to alterations in the extracellular matrix, changes in smooth muscle content, endothelial injury and atherosclerotic lesion formation. Favorable alterations in any of these variables could bring about improvements in arterial stiffness (6).

Vascular remodeling is a possible consequence of hypertension due to glucocorticoid excess. Hypertrophic changes in the morphology of small-resistance arteries (increased media to lumen ratio, media thickness and wall thickness) havebeen described in patientswith CS. Increased vascular endothelial growth factor (VEGF), a potent angiogenic factor, has been reported to be responsible for vasculature remodeling in various experimental models of glucocorticoid excess. Hyperinsulinemia, impaired insulin signaling and insulin/insulin-like growth factor 1 (IGF1) receptors hybrid formation have been claimed to play a role in vasculature smooth muscle cell dysfunction. Glucocorticoids can activate the RAS (7), and angiotensin 2 was found to upregulate LDL receptor-related protein 1 (LRP1) expression, which could aggregate low-density

$$
\begin{array}{lr}
\text { http://www.endocrineconnections.org } & \text { O2018 The authors } \\
\text { https://doi.org/10.1530/EC-18-0010 } & \text { Published by Bioscientifica Ltd }
\end{array}
$$

lipoprotein (LDL) uptake in vascular cells (8). This vascular remodeling and dysfunction may contribute to the aggravation of hypertension associated with hypercortisolism.

Intensive cholesterol reduction may be beneficial in the treatment of patients with hypertension and normal lipid levels, through a reduction in large artery stiffness. Ferrier found an additional statin therapy led to a greater reduction in systolic blood pressure (SBP), mean arterial pressure (MAP) and diastolic blood pressure (DBP) (6).

However, the relationship between plasma lipids and hypertension in patients with $\mathrm{CD}$ has not been investigated. Therefore, we described lipid profile and explored pathogenetic role of LDL-c on hypertension in patients with $\mathrm{CD}$.

\section{Materials and methods}

\section{Study population}

This retrospective study included 84 patients referring to the endocrine departments of Huashan Hospital for diagnosis and evaluation of CD from January 2012 to December 2013. Seventy females and fourteen males were enrolled. All subjects had detailed clinical evaluation by the same group of endocrinology specialists to avoid the subjective influences. Consent has been obtained from each patient or subject after full explanation of the purpose and nature of all procedures used. Our study was approved by the Ethics Committee of Huashan Hospital, Fudan University (No. 2017M-011).

\section{Diagnostic methods}

The 24-h UFC excretion, the overnight $1 \mathrm{mg}$ dexamethasone suppression test (DST) and cortisol secretion circadian rhythm were used as the first-line screen tests to identify patients with CS after exclusion of exogenous glucocorticoids exposure, cyclical Cushing's syndrome (CCS) and other complications (e.g. infection, tumor). The diagnostic criteria included (1) elevated levels of 24-h UFC (average of at least 2 samples); (2) failure of plasma cortisol decrease $<5 \mu \mathrm{g} / \mathrm{dL}$ after overnight $1 \mathrm{mg}$ DST and (3) disorder of serum cortisol secretion circadian rhythm (samples collected at 00:00, 08:00, 16:00). Plasma and free urinary cortisol levels were performed by radioimmunoassay (RIA) (Roche Diagnostic). Adrenocorticotroph hormone (ACTH)-dependent CS was diagnosed based on an unsuppressed ACTH level. Plasma

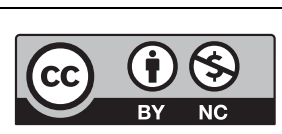

This work is licensed under a Creative Commons Attribution-NonCommercial 4.0 International License. 
ACTH was measured in an automated chemiluminescence immunoassay (Siemens Healthcare Diagnostics). CD was clinically diagnosed by lesion $>6 \mathrm{~mm}$ in pituitary magnetic resonance imaging (MRI) scan or positive results in inferior petrosal sinus sampling (IPSS) selectively performed in patients with negative image in MRI or mass less than $6 \mathrm{~mm}$. CD was then confirmed pathologically after tanssphenoidal surgery (positive immunochemistry staining with ACTH). The intraassay and interassay coefficients of variation were $5 \%$ and $10 \%$, respectively.

\section{Clinical and biochemical methods}

Body mass index (BMI) and blood pressure were measured at the same condition at diagnosis. Hemoglobin, plasma potassium $\left(\mathrm{K}^{+}\right)$, hepatic function, creatinine, hemoglobin A1c (HbA1c), lipid profile and gonadal hormone were evaluated by standard methods.

At all time points, a detailed medical history was obtained, and a complete physical examination was performed, including measurements of weight, height by stadiometer and blood pressure. Blood pressure was taken in all patients twice a day using appropriate size cuffs and BMI was calculated using the formula weight $(\mathrm{kg}) /$ height $^{2}\left(\mathrm{~m}^{2}\right)$.

\section{Statistical analysis}

Data are presented as median (range), unless otherwise indicated. Pearson correlation coefficients were used for correlation analyses. Linear regression was used to build prediction models of SBP from each predictor of interest respectively (cholesterol (CHO), triglyceride (TG), highdensity lipoprotein-cholesterol (HDL-c), LDL-cholesterol (LDL-c), apolipoproteinA (apoA), apolipoproteinB (apoB) and lipoprotein(a) $(\mathrm{LP}(\mathrm{a})))$. The covariates of such models were M1 is a regression model including just plasma lipid respectively; M2 adds age, gender and BMI to the predictors of M1; M3 adds plasma $\mathrm{K}^{+}$to the predictors of M2; M4 adds plasma cortisol (F) to the predictors of M3; M5 adds HbA1c to the predictors of M4; M6 adds number of anti-hypertensive drugs to the predictors of M5; M7 adds statin use to the predictors of M6 and M8 adds course of the disease to the predictors of M7. Values are unstandardized coefficients and STD errors (in brackets). Multivariable regression splines were used to take into account non-linear relationships between the continuous covariates and the outcome. Data were analyzed using SAS system software, version 9.2 (SAS Institute, Cary, NC, USA). A two-sided $P<0.05$ was considered statistically significant.

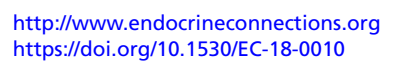

\section{Results}

A total of 84 patients were enrolled in the study. Of these 84 patients, 65 patients had hypertension. In patients with hypertension, 53 took anti-hypertensive therapy (Fig. 1). The ratio of treated controlled and uncontrolled hypertension was 46/53 and 7/53. Demographic and clinical characteristics in patients with CD are shown in Table 1. No significant differences were found between LDL-c $<3.37 \mathrm{mmol} / \mathrm{L}$ and LDL-c $\geq 3.37 \mathrm{mmol} / \mathrm{L}$ group in age, F, ACTH, 24-h UFC, $\mathrm{K}^{+}$, HbA1c and HDL-c. High LDL-c patients had significant higher BMI, SBP, TG, CHO and higher apoB level between two groups $(P<0.05)$.

An association was detected between SBP values and lipid profile including $\mathrm{CHO}(r=0.309, P=0.005)$, TG $(r=0.306, P=0.005)$, LDL-c $(r=0.275, P=0.012)$, apoA $(r=0.051, P=0.653)$, apoB $(r=0.366, P=0.001)$ and LP(a) $(r=-0.205, P=0.067)$. We determined to further explore the association between SBP values and lipid profile when covariates adjusted. When F, ACTH, UFC, BMI, HbA1c and course of the disease were adjusted, significant association was still detected (Table 2).

Multivariate regression analyses of the association between SBP and lipid profile are shown in Table 3. After adjustment for all covariates including age, gender, BMI, plasma $\mathrm{K}^{+}, \mathrm{F}, \mathrm{HbA1c}$ and number of anti-hypertensive drugs, the LDL-c remained positively associated with SBP.

The mean \pm s.D. values of the SBP of 84 patients with CD are shown in Fig. 2. In 67 patients without taking statins, patients with LDL-c $<3.37$ had significantly lower SBP than patients with LDL-c $\geq 3.37,132.7 \pm 16.1 \mathrm{mmHg}$ and $141.5 \pm 15.1 \mathrm{mmHg}(P<0.05)$. In 17 patients taking statins,

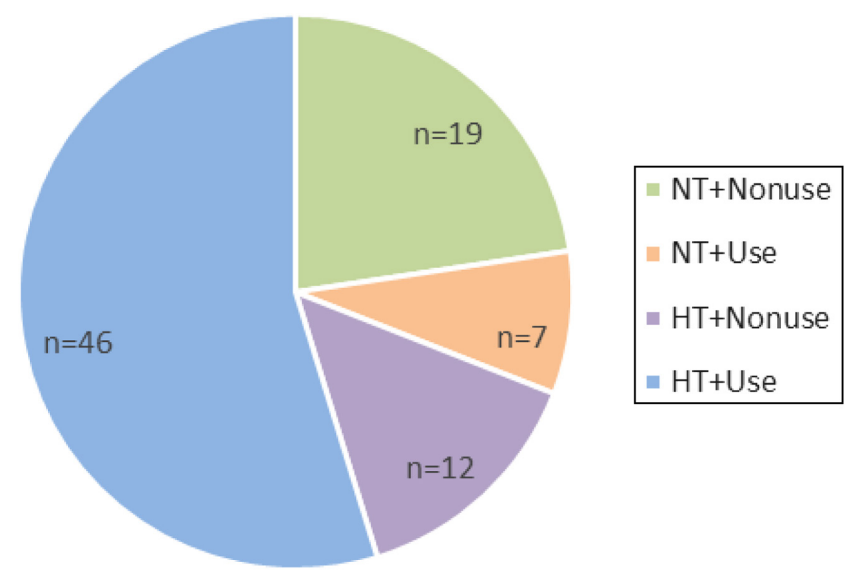

Figure 1

Distribution of hypertension and anti-hypertensive therapy in patients with CD. NT, normotensive ( $<140 / 90 \mathrm{mmHg}) ; \mathrm{HT}$, hypertensive $(\geq 140 / 90 \mathrm{mmHg}$ ); Use, patients who took antihypertensive therapy; Nonuse, patients who did not take antihypertensive therapy.

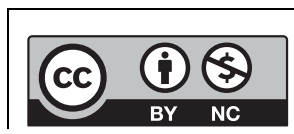

This work is licensed under a Creative Commons Attribution-NonCommercial 4.0 International License. 
Table 1 Clinical characteristics in patients with CD.

\begin{tabular}{|c|c|c|c|c|}
\hline & Total $(n=84)$ & LDL-c $<3.37 \mathrm{mmol} / \mathrm{L}(n=47)$ & LDL-c $\geq 3.37 \mathrm{mmol} / \mathrm{L}(n=37)$ & $\boldsymbol{P}$ \\
\hline Age (years) & $33.5(14.0-62.0)$ & $37.0(14.0-62.0)$ & $30.0(14.0-62.0)$ & $0.322^{\dagger}$ \\
\hline BMI $\left(\mathrm{kg} / \mathrm{m}^{2}\right)$ & $24.6(17.1-35.8)$ & $23.8(17.1-34.3)$ & $26.5(19.5-35.9)$ & $0.024^{\dagger}$ \\
\hline $\mathrm{F}(\mu \mathrm{g} / \mathrm{dL})$ & $28.0(8.8-63.0)$ & $27.6(8.8-58.3)$ & $29.8(15.9-63.4)$ & $0.131^{\dagger}$ \\
\hline АСТН $(\mathrm{pg} / \mathrm{mL})$ & $75.1(55.5-120.8)$ & $72.2(21.0-231.0)$ & $77.0(27.0-238.0)$ & $0.234^{\dagger}$ \\
\hline UFC ( $\mu \mathrm{g} / 24 \mathrm{~h})$ & $479(81-6869)$ & $445(80-6869)$ & 645 (135-2920) & $0.296^{\dagger}$ \\
\hline $\mathrm{K}(\mathrm{mmol} / \mathrm{L})$ & $4.1(2.2-5.2)$ & $4.1(2.2-5.2)$ & $4.1(2.3-5.0)$ & $0.867^{\dagger}$ \\
\hline HbA1c (\%) & $5.9(4.6-11.5)$ & $5.8(4.6-11.5)$ & $6.1(5.2-9.8)$ & $0.641^{\dagger}$ \\
\hline $\mathrm{SBP}(\mathrm{mmHg})$ & $138(125-151)$ & $136(102-170)$ & $150(115-180)$ & $0.001^{\dagger}$ \\
\hline $\mathrm{DBP}(\mathrm{mmHg})$ & $92(85-100)$ & $90(69-130)$ & $96(63-120)$ & $0.045^{\dagger}$ \\
\hline $\mathrm{CHO}(\mathrm{mmol} / \mathrm{L})$ & $5.4(3.4-9.0)$ & $4.75(3.37-6.25)$ & $6.56(5.01-9.0)$ & $0.000^{\dagger}$ \\
\hline TG $(\mathrm{mmol} / \mathrm{L})$ & $1.5(0.4-9.0)$ & $1.33(0.4-3.39)$ & $1.8(0.84-6.1)$ & $0.000^{\dagger}$ \\
\hline HDL-c (mmol/L) & $1.4(0.8-2.7)$ & $1.4(0.8-2.7)$ & $1.5(0.8-2.3)$ & $0.524^{\dagger}$ \\
\hline LDL-c (mmol/L) & $3.2(1.6-6.0)$ & $2.7(1.6-3.4)$ & $4.1(3.4-6.0)$ & $0.000^{\dagger}$ \\
\hline ApoA $(\mathrm{mmol} / \mathrm{L})$ & $1.2(0.6-1.9)$ & $1.2(0.6-1.9)$ & $1.1(0.8-2.0)$ & $0.383^{\dagger}$ \\
\hline $\mathrm{ApoB}(\mathrm{mmol} / \mathrm{L})$ & $0.8(0.4-2.0)$ & $0.7(0.5-0.9)$ & $1.1(0.8-2.1)$ & $0.000^{\dagger}$ \\
\hline $\mathrm{LP}(\mathrm{a})(\mathrm{mmol} / \mathrm{L})$ & $100(3-1611)$ & $100(3-1611)$ & $100(11-611)$ & $0.877^{\dagger}$ \\
\hline Anti-hypertensive drugs ( $n$ ) & $1(0-4)$ & $1(0-3)$ & $1(0-3)$ & $0.295^{\dagger}$ \\
\hline Statin usage $(n, \%)$ & $17(20.7)$ & $6(12.8)$ & $11(31.4)$ & $0.039^{\ddagger}$ \\
\hline Course of the disease (month) & $37.5(17.0-66.0)$ & $33.0(0.0-223.0)$ & $53.0(3.0-130.0)$ & $0.077^{\dagger}$ \\
\hline
\end{tabular}

Data are presented as the median (range) or $n$ (percentage).

${ }^{\dagger}$ Mann-Whitney test; ${ }^{*}$ chi-square test.

BMI, body mass index; CHO, cholesterol; DBP, diastolic blood pressure; HDL-c, high-density lipoprotein cholesterol; LDL-c, low-density lipoprotein cholesterol; $n$, number; SBP, systolic blood pressure; TG, triglyceride.

patients with LDL-c $<3.37$ also had significantly lower SBP than patients with LDL-c $\geq 3.37,139.3 \pm 13.2 \mathrm{mmHg}$ and $154.6 \pm 13.2 \mathrm{mmHg}(P<0.05)$.

LDL-c was coded using an RCS function with three knots located at the 5th, 50th and 95th percentiles of the distribution of LDL-c (Fig. 3). $Y$-axis represents the difference in SBP between individuals with any value of LDL-c with individuals with $3.215 \mathrm{mmol} / \mathrm{L}$ of LDL-c. Dashed lines are 95 per cent confidence intervals (CI). Knots are represented by dots.

Compared to individuals with $3.215 \mathrm{mmol} / \mathrm{L}$ of LDLc, individuals with $4.0,4.5$ and $5.0 \mathrm{mmol} / \mathrm{L}$ of LDL-c had differences of 3.86 (95\% CI: 1.02-6.71), 8.53 (95\% CI:
3.10-13.96), 14.11 (95\% CI: 5.31-22.91) $\mathrm{mmHg}$ in SBP, respectively. We speculated possible threshold level of LDL-c for hypertension was $3.215 \mathrm{mmol} / \mathrm{L}$.

\section{Discussion}

This study presented a potential mechanism of hypertension in CD. In this study, there was no association found between blood pressure and F, UFC, ACTH or serum glucose level in CD patients. However, SBP in CD was significantly related with lipid profile (CHO, TG, LDL-c and apoB) independent of multiple covariates. As expected,

Table 2 Pearson and partial correlations between SBP and lipid profile.

\begin{tabular}{|c|c|c|c|c|c|c|c|}
\hline & \multirow[b]{2}{*}{ SBP $^{+}$} & \multicolumn{6}{|c|}{ SBP ${ }^{\neq}$} \\
\hline & & $\mathrm{F}$ & ACTH & UFC & $\mathrm{BMI}$ & $\mathrm{HbA1c}$ & $\begin{array}{c}\text { Course of the } \\
\text { disease }\end{array}$ \\
\hline $\mathrm{CHO}(\mathrm{mmol} / \mathrm{L})$ & $0.309(0.005)$ & $0.313(0.020)$ & $0.308(0.005)$ & $0.321(0.003)$ & $0.287(0.009)$ & $0.406(0.001)$ & $0.291(0.008)$ \\
\hline TG (mmol/L) & $0.306(0.005)$ & $0.352(0.008)$ & $0.303(0.006)$ & $0.321(0.003)$ & $0.260(0.019)$ & $0.247(0.044)$ & $0.291(0.008)$ \\
\hline HDL-c (mmol/L) & $-0.024(0.832)$ & $-0.092(0.503)$ & $-0.020(0.862)$ & $-0.034(0.761)$ & $0.017(0.880)$ & $0.135(0.277)$ & $-0.012(0.918)$ \\
\hline LDL-c (mmol/L) & $0.275(0.012)$ & $0.297(0.028)$ & $0.273(0.014)$ & $0.288(0.009)$ & $0.253(0.023)$ & $0.344(0.004)$ & $0.255(0.022)$ \\
\hline ApoA (mmol/L) & $0.051(0.653)$ & $-0.089(0.516)$ & $0.050(0.660)$ & $0.032(0.781)$ & $0.065(0.565)$ & $0.160(0.196)$ & $0.067(0.558)$ \\
\hline ApoB (mmol/L) & $0.366(0.001)$ & $0.402(0.002)$ & $0.363(0.001)$ & $0.362(0.001)$ & $0.334(0.002)$ & $0.396(0.001)$ & $0.349(0.002)$ \\
\hline LP(a) (mmol/L) & $-0.205(0.067)$ & $-0.225(0.099)$ & $-0.202(0.073)$ & $-0.207(0.066)$ & $-0.184(0.102)$ & $-0.194(0.116)$ & $-0.211(0.060)$ \\
\hline
\end{tabular}

Data are presented as correlation coefficient ( $P$ value).

${ }^{\dagger}$ Pearson correlations: between SBP values and lipids profile including CHO, TG, LDL-C, apoA, apoB and LP(a); ${ }^{\ddagger}$ Partial correlations adjusted for each variable: between SBP values and lipid profile when F, ACTH, UFC, BMI, HbA1c and course of the disease were adjusted.

$$
\begin{array}{lr}
\text { http://www.endocrineconnections.org } & \text { O2018 The authors } \\
\text { https://doi.org/10.1530/EC-18-0010 } & \text { Published by Bioscientifica Ltd }
\end{array}
$$


Table 3 Accuracy of the prediction of SBP from CHO, TG, HDL-C, LDL-C, apoA, apoB and LP(a) adjusting other covariates.

\begin{tabular}{|c|c|c|}
\hline & \multicolumn{2}{|c|}{ CHO } \\
\hline & $\beta$ (S.E.) & $P$ \\
\hline M1 & $4.3(1.5)$ & 0.005 \\
\hline M2 & $4.1(1.5)$ & 0.007 \\
\hline M3 & $4.1(1.4)$ & 0.007 \\
\hline M4 & $4.1(1.5)$ & 0.007 \\
\hline M5 & $5.5(1.6)$ & 0.001 \\
\hline M6 & $4.1(1.5)$ & 0.007 \\
\hline M7 & $3.7(1.5)$ & 0.021 \\
\hline M8 & $3.6(1.6)$ & 0.030 \\
\hline
\end{tabular}

\begin{tabular}{|c|c|c|c|}
\hline \multicolumn{2}{|c|}{ HDL-C } & \multicolumn{2}{|c|}{ LDL-c } \\
\hline$\beta$ (S.E.) & $P$ & $\beta$ (S.E.) & $P$ \\
\hline$-1.1(5.2)$ & 0.832 & $4.7(1.9)$ & 0.012 \\
\hline $2.6(5.4)$ & 0.626 & $4.6(1.8)$ & 0.015 \\
\hline $2.3(5.3)$ & 0.663 & 4.9 (1.9) & 0.010 \\
\hline $2.3(5.4)$ & 0.665 & 4.9 (1.9) & 0.011 \\
\hline 9.7 (5.7) & 0.097 & $6.0(2.0)$ & 0.005 \\
\hline $7.8(4.9)$ & 0.122 & $4.6(1.9)$ & 0.016 \\
\hline $7.3(4.9)$ & 0.142 & $4.1(1.9)$ & 0.037 \\
\hline $8.6(5.0)$ & 0.094 & $4.0(2.0)$ & 0.045 \\
\hline
\end{tabular}

\begin{tabular}{|c|c|}
\hline \multicolumn{2}{|c|}{ TG } \\
\hline$\beta$ (S.E.) & $P$ \\
\hline $5.1(1.8)$ & 0.005 \\
\hline $4.1(1.9)$ & 0.042 \\
\hline $3.3(2.0)$ & 0.105 \\
\hline $3.3(2.0)$ & 0.107 \\
\hline $2.5(2.3)$ & 0.266 \\
\hline $2.7(4.5)$ & 0.548 \\
\hline$-0.2(2.1)$ & 0.929 \\
\hline$-0.7(2.2)$ & 0.758 \\
\hline
\end{tabular}

\begin{tabular}{|c|c|}
\hline \multicolumn{2}{|c|}{ ApoA } \\
\hline$\beta$ (S.E.) & $P$ \\
\hline $3.5(7.6)$ & 0.653 \\
\hline $4.9(7.5)$ & 0.509 \\
\hline $5.4(7.4)$ & 0.466 \\
\hline $5.6(7.5)$ & 0.451 \\
\hline $12.2(8.1)$ & 0.138 \\
\hline $11.5(6.9)$ & 0.102 \\
\hline $10.1(7.0)$ & 0.153 \\
\hline $12.3(7.2)$ & 0.093 \\
\hline
\end{tabular}

\begin{tabular}{|c|c|}
\hline \multicolumn{2}{|c|}{ Аров } \\
\hline$\beta$ (S.E.) & $P$ \\
\hline $21.2(6.1)$ & 0.001 \\
\hline $18.9(6.3)$ & 0.004 \\
\hline $19.3(6.2)$ & 0.003 \\
\hline $19.2(6.3)$ & 0.003 \\
\hline 20.9 (6.7) & 0.003 \\
\hline $15.9(6.0)$ & 0.010 \\
\hline $14.2(6.3)$ & 0.029 \\
\hline $14.1(6.8)$ & 0.044 \\
\hline
\end{tabular}

\begin{tabular}{|c|c|}
\hline \multicolumn{2}{|c|}{$\mathbf{L P}(\mathrm{a})$} \\
\hline$\beta$ (S.E.) & $P$ \\
\hline$-0.0(0.0)$ & 0.067 \\
\hline$-0.0(0.0)$ & 0.153 \\
\hline$-0.0(0.0)$ & 0.215 \\
\hline$-0.0(0.0)$ & 0.239 \\
\hline$-0.0(0.0)$ & 0.357 \\
\hline$-0.0(0.0)$ & 0.315 \\
\hline$-0.0(0.0)$ & 0.616 \\
\hline$-0.0(0.0)$ & 0.553 \\
\hline
\end{tabular}

$\mathrm{M} 1$ is a regression model including just plasma lipid respectively; M2 adds age, gender and BMI to the predictors of M1; M3 adds plasma $\mathrm{K}^{+}$to the predictors of M2; M4 adds F to the predictors of M3; M5 adds HbA1c to the predictors of M4; M6 adds number of anti-hypertensive drugs to the predictors of M5; M7 adds statin use to the predictors of M6; M8 adds course of the disease to the predictors of M7. Values are unstandardized coefficients and STD errors (in brackets).

the results strongly suggested that CHO, LDL-c and apoB might predict hypertension more precisely in $\mathrm{CD}$.

Arterial hypertension is a common feature in CD. The hypertension of endogenous hypercortisolism is characterized by disruption of the blood pressure circadian rhythm, with loss of the physiologically observed nocturnal fall. However, hypertension may persist in CD patients after surgical cure, presumably because of vessel remodeling and/or underlying essential hypertension (1). Multiple mechanisms have been proved to be involved in the development of hypertension in $\mathrm{CD}$, including the RAS, mineralocorticoid activity, sympathetic nervous system, vasoregulatory system, metabolic factor, vascular factor and sleep apnea as such (2). On the other hand, there is an increase in circulating very lowdensity lipoprotein (VLDL) and LDL, but not HDL, with consequent elevation of TG and CHO levels in $\mathrm{CD}$, which may account for hypertension as well. The mechanisms for hyperlipidemia are probably multifactorial, including direct cortisol influences on lipoprotein synthesis, free fatty acid production and hepatic endothelial lipase activity (9). Moreover, the causes of hypertension in CD such as angiotensin 2 (8), insulin resistance (9) and sleep apnea (10) also play important roles in the determination of lipid abnormalities.

During the past decades, multiple studies have presented the relationship between hypertension and lipid profile in non-CD population $(11,12,13)$. In the Physicians' Health Study, CHO, non-HDL-c and the CHO/ HDL-c ratio predicted onset of hypertension in 3110 men without self-reported hypertension, indicating that hypertension might be a consequence of dyslipidemia or closely related metabolic abnormalities (14). Additionally, TG and apoB were also shown to be positively associated with increased risk of hypertension in middle-aged Finnish men (15). Greater risk of hypertension was demonstrated

$$
\begin{array}{lr}
\text { http://www.endocrineconnections.org } & \text { O2018 The authors } \\
\text { https://doi.org/10.1530/EC-18-0010 } & \text { Published by Bioscientifica Ltd }
\end{array}
$$

associated with higher total concentrations of LDL and HDL particles, especially small particles, and higher total concentration of VLDL, especially large particles (16). In Nigerians and Bangladesh, patients with hypertension were more likely than normotensive patients to exhibit dyslipidemia, including elevated $\mathrm{CHO}$, LDL-c, TG and reduced HDL-c levels $(17,18)$. However, previous studies did not accentuate these interrelated variables $(\mathrm{CHO}$, LDL-c and apoB) and their relationship with SBP per se, in $\mathrm{CD}$ particularly.

SBP is an integrated measure of steady and pulsatile pressure load. In young adults, higher SBP may be attributable to increased cardiac output (non-obese patients particularly) (19). In middle-aged and older

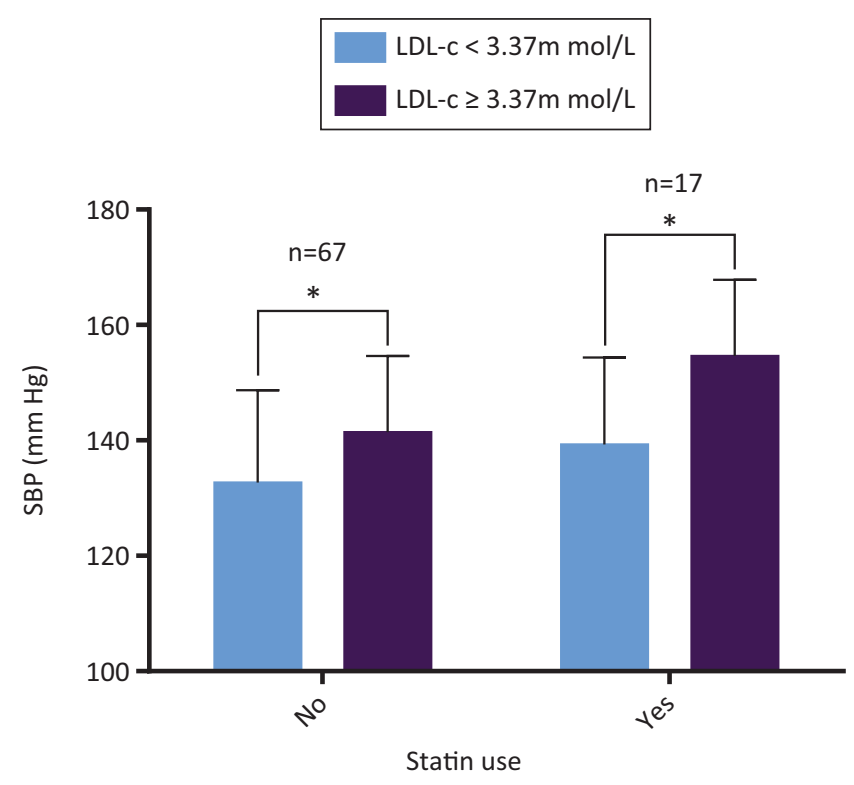

Figure 2

Relationship between SBP $(\mathrm{mmHg})$ and LDL-c $(\mathrm{mmol} / \mathrm{L})$ level stratified by statins use in patients with $C D\left({ }^{*} P<0.05\right)$.

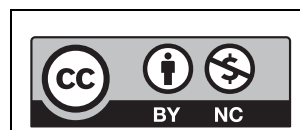

This work is licensed under a Creative Commons Attribution-NonCommercial 4.0 International License. 


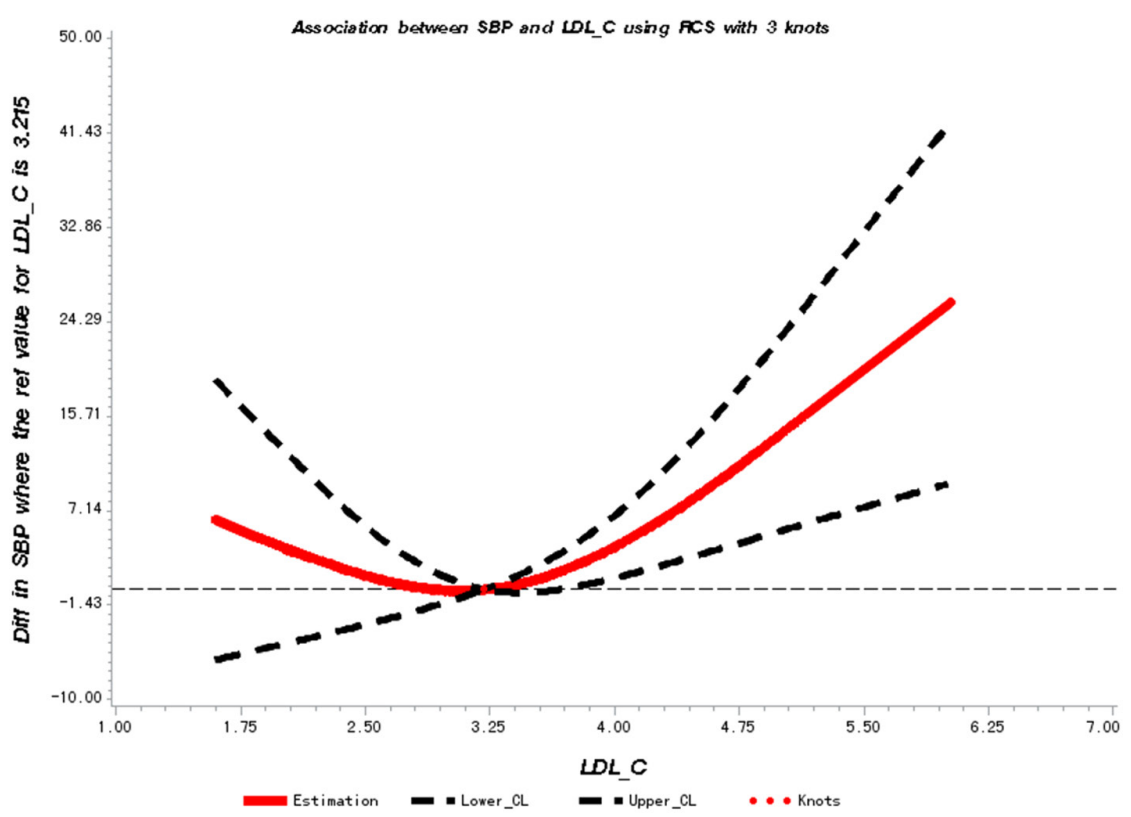

Figure 3

Adjusted dose-response association between LDL-c $(\mathrm{mmol} / \mathrm{L})$ and SBP $(\mathrm{mmHg})$ in patients with CD. adults, increased aortic stiffness and reduced aortic diameter may lead to mismatch between pressure and flow (20). On the other hand, DBP is representative of resistant vessel structure and function alterations (21). As to our study, dyslipidemia including $\mathrm{CHO}$, LDL-c and apoB may contribute to vessel stiffness and consequently lead to high SBP other than DBP.

Postulated mechanisms for the relationship between hypertension and dyslipidemia in CD have not been fully clarified. First of all, endothelial dysfunction likely plays a role. As mentioned, glucocorticoids can activate the RAS (7), which is an important mechanism of hypertension in CD. Moreover, angiotensin 2 was found to upregulate LRP1 expression, which could aggregate LDL uptake in vascular cells (8), and LDL-c has been shown to increase peripheral vascular resistance and arterial stiffness thus to arterial hypertension (15). One of the mechanisms that LDL-c affects blood pressure has been shown through angiotensin 2 type 1 (AT1) receptor. Multiple studies found that LDL-c led to a profound increase of AT1 receptor expression in vascular smooth muscle cells, which was involved in endothelial dysfunction $(22,23)$, and LDL reduction by simvastatin was accompanied by AT1 receptor downregulation (24). Besides, dyslipidemia and others related to insulin resistance, a feature of CD, have been reported associated with decreased arterial compliance of the carotid artery (25). Secondly, Brinkley observed that higher ox-LDLs were related to higher LDL and described higher arterial stiffness in the group with higher ox-LDL values (26). All of hyperglycemia, hyperinsulinemia and hypertension in CD patients can

http://www.endocrineconnections.org https://doi.org/10.1530/EC-18-0010

O2018 The authors Published by Bioscientifica Ltd induce oxidative stress, release oxygen free radicals from inflammatory cells and then promote the oxidation of LDL to ox-LDL. Glucose can also directly react with LDL phospholipids and apoB lysine groups to form the advanced glycation end products (AGEs) that facilitate lipid peroxidation (27). Thirdly, nuclear hormone receptor family, liver $\mathrm{X}$ receptor (LXR, a potential regulator of renin expression which is involved in $\mathrm{CD}$ ), may be a mediator. LXRa is physiologically activated during lipid loading, and the expression and activation of LXRa inside the atherosclerotic plaque have been described (28). These studies have suggested a cross-talk between lipid metabolism disorders and blood pressure regulation through nuclear hormone receptors.

Blood pressure reduction has previously been reported with cholesterol reduction in hyperlipidemia patients. The large Fenofibrate Intervention and Event Lowering in Diabetes (FIELD) study and the Brisighella Heart Study have found a small decrease in blood pressure with fibrates and statin $(29,30)$. In a meta-analysis of randomized controlled trials of statin therapy, statin use decreased SBP compared with placebo (31). Some other investigations demonstrated that additional statin therapy led to a greater reduction in SBP, MAP and DBP in patients with controlled hypertension who were also hypercholesterolemic $(32,33)$. Moreover, the reduction in large artery stiffness observed in statin treatment was speculated to be the result of statin-mediated improvement in endothelial function. The same group found that the magnitude of reduction in arterial stiffness with statin therapy was correlated with the degree of LDL-c lowering,

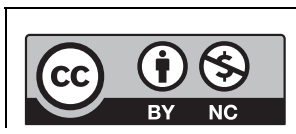

This work is licensed under a Creative Commons Attribution-NonCommercial 4.0 International License. 
suggesting that lipid lowering contributed, at least in part, to this effect (34).

There were some limitations in our study. This was a cross-sectional study, so it did not show causal relationship. Besides, the relatively small number of subjects needed to be considered. Therefore, the conclusions would be testified by large-scale studies, and longitudinal follow-up along with interventional studies were necessary in the following investigations.

Treatment of endogenous hypercortisolism usually results in resolution or amelioration of hypertension. As previously mentioned, some patients may not achieve normotension or may require a prolonged period of time for the correction of hypercortisolism, and these patients usually need concomitant or sequential use of multiple anti-hypertensive treatment including lipid-lowing therapy particularly to reduce blood pressure and the duration of hypertension.

\section{Conclusion}

Our study found that blood pressure in CD patients was significantly associated with serum lipid profile (CHO, LDL-c and apoB in particular). The non-linear relationship between blood pressure and LDL-c indicated the potential role of LDL-c in vessel remodeling, thus increasing cardiovascular events. Therefore, investigations of the beneficial effects of lipid-lowing treatment on hypertension and cardiovascular events in CD patients were necessary in the future. Based on our results, aortic stiffness should be considered in anti-hypertension therapy, which suggested additional lipid-lowing treatment in CD patients.

\section{Declaration of interest}

The authors declare that there is no conflict of interest that could be perceived as prejudicing the impartiality of the research reported.

\section{Funding}

This work was supported by grants from the Project of the National Natural Science Foundation of China (NSFC 81471083 and 81270955).

\section{Author contribution statement}

Zhaoyun Zhang, Yehong Yang, Yongfei Wang, Yiming Li and Hongying Ye conceived and designed the research. Lang Qin, Xiaoxia Liu, Xiaoming Zhu, Meifang Zeng, Ran Tao, Yan Zhuang and Yiting Zhou performed the research. Xiaoming Zhu and Hongying Ye analyzed the data. Lang Qin, Xiaoxia Liu, Xiaoming Zhu and Hongying Ye wrote the paper. Yiming Li and Hongying Ye commented on the manuscript. Meifang Zeng, Ran Tao, Yan Zhuang and Yiting Zhou recruited patients.

\section{Acknowledgments}

The authors are indebted to the patients who participated in this study, and to all the doctors involved in the diagnosis and treatment of these patients.

\section{References}

1 Magiakou MA, Smyrnaki P \& Chrousos GP. Hypertension in Cushing's syndrome. Best Practice and Research: Clinical Endocrinology and Metabolism 200620 467-482. (https://doi.org/10.1016/j. beem.2006.07.006)

2 Isidori AM, Graziadio C, Paragliola RM, Cozzolino A, Ambrogio AG, Colao A, Corsello SM \& Pivonello R. The hypertension of Cushing's syndrome: controversies in the pathophysiology and focus on cardiovascular complications. Journal of Hypertension 201533 44-60. (https://doi.org/10.1097/HJH.0000000000000415)

3 Cicala MV \& Mantero F. Hypertension in Cushing's syndrome: from pathogenesis to treatment. Neuroendocrinology 201092 (Supplement 1) 44-49. (https://doi.org/10.1159/000314315)

4 Lodish MB, Sinaii N, Patronas N, Batista DL, Keil M, Samuel J, Moran J, Verma S, Popovic J \& Stratakis CA. Blood pressure in pediatric patients with Cushing syndrome. Journal of Clinical Endocrinology and Metabolism 200994 2002-2008. (https://doi. org/10.1210/jc.2008-2694)

5 Magiakou MA, Mastorakos G, Zachman K \& Chrousos GP. Blood pressure in children and adolescents with Cushing's syndrome before and after surgical care. Journal of Clinical Endocrinology and Metabolism 199782 1734-1738. (https://doi.org/10.1210/ jcem.82.6.3985)

6 Ferrier KE, Muhlmann MH, Baguet JP, Cameron JD, Jennings GL, Dart AM \& Kingwell BA. Intensive cholesterol reduction lowers blood pressure and large artery stiffness in isolated systolic hypertension. Journal of the American College of Cardiology 200239 1020-1025. (https://doi.org/10.1016/S0735-1097(02)01717-5)

7 Suzuki H, Handa M, Kondo K \& Saruta T. Role of renin-angiotensin system in glucocorticoid hypertension in rats. American Journal of Physiology 1982243 E48-E51. (https://doi.org/10.1152/ ajpendo.1982.243.1.E48)

8 Sendra J, Llorente-Cortes V, Costales P, Huesca-Gomez C \& Badimon L. Angiotensin II upregulates LDL receptor-related protein (LRP1) expression in the vascular wall: a new pro-atherogenic mechanism of hypertension. Cardiovascular Research $2008 \mathbf{7 8}$ 581-589. (https://doi.org/10.1093/cvr/cvn043)

9 Arnaldi G, Angeli A, Atkinson AB, Bertagna X, Cavagnini F, Chrousos GP, Fava GA, Findling JW, Gaillard RC, Grossman AB, et al. Diagnosis and complications of Cushing's syndrome: a consensus statement. Journal of Clinical Endocrinology and Metabolism $2003 \mathbf{8 8}$ 5593-5602. (https://doi.org/10.1210/jc.2003-030871)

10 de Sousa RC \& Lira AB. Correlation between the severity of apnea and hypopnea sleep, hypertension and serum lipid and glycemic: a case control study. European Archives of Oto-Rhino-Laryngology 2015 272 1509-1515. (https://doi.org/10.1007/s00405-014-3076-5)

11 Landray MJ, Edmunds E, Li-Saw-Hee FL, Hughes BA, Beevers DG, Kendall MJ \& Lip GY. Abnormal low-density lipoprotein subfraction profile in patients with untreated hypertension. Quarterly Journal of Medicine 200295 165-171. (https://doi.org/10.1093/qjmed/95.3.165)

12 Kim YK, Seo HS, Lee EM, Na JO, Choi CU, Lim HE, Kim EJ, Rha SW, Park CG \& Oh DJ. Association of hypertension with small, dense low-density lipoprotein in patients without metabolic syndrome. Journal of Human Hypertension 201226 670-676. (https://doi. org/10.1038/jhh.2011.86)

13 Takiwaki M, Tomoda F, Koike T, Taki T, Inoue H, Kigawa M, Kitajima I \& Uji Y. Increased levels of small dense low-density lipoprotein cholesterol associated with hemorheological abnormalities in

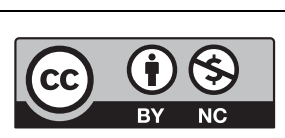

This work is licensed under a Creative Commons Attribution-NonCommercial 4.0 International License. 
untreated, early-stage essential hypertensives. Hypertension Research 201437 1008-1013. (https://doi.org/10.1038/hr.2014.111)

14 Halperin RO, Sesso HD, Ma J, Buring JE, Stampfer MJ \& Gaziano JM. Dyslipidemia and the risk of incident hypertension in men. Hypertension 200647 45-50. (https://doi.org/10.1161/01. HYP.0000196306.42418.0e)

15 Laaksonen DE, Niskanen L, Nyyssonen K, Lakka TA, Laukkanen JA \& Salonen JT. Dyslipidaemia as a predictor of hypertension in middleaged men. European Heart Journal 200829 2561-2568. (https://doi. org/10.1093/eurheartj/ehn061)

16 Paynter NP, Sesso HD, Conen D, Otvos JD \& Mora S. Lipoprotein subclass abnormalities and incident hypertension in initially healthy women. Clinical Chemistry 201157 1178-1187. (https://doi org/10.1373/clinchem.2011.167544)

17 Saidu H, Karaye KM \& Okeahialam BN. Plasma lipid profile in Nigerians with high-normal blood pressure. BMC Research Notes 2014 7 930. (https://doi.org/10.1186/1756-0500-7-930)

18 Choudhury KN, Mainuddin AK, Wahiduzzaman M \& Islam SM. Serum lipid profile and its association with hypertension in Bangladesh. Vascular Health and Risk Management 201410 327-332. (https://doi.org/10.2147/VHRM.S61019)

19 Yano Y \& Lloyd-Jones DM. Isolated systolic hypertension in young and middle-aged adults. Current Hypertension Reports 20161878. (https://doi.org/10.1007/s11906-016-0686-x)

20 Mitchell GF, Conlin PR, Dunlap ME, Lacourciere Y, Arnold JM, Ogilvie RI, Neutel J, Izzo JJ \& Pfeffer MA. Aortic diameter, wall stiffness, and wave reflection in systolic hypertension. Hypertension 200851 105-111. (https://doi.org/10.1161/ HYPERTENSIONAHA.107.099721)

21 Franklin SS, Gustin WT, Wong ND, Larson MG, Weber MA, Kannel WB \& Levy D. Hemodynamic patterns of age-related changes in blood pressure. The Framingham Heart Study. Circulation 199796 308-315. (https://doi.org/10.1161/01.CIR.96.1.308)

22 Strehlow K, Wassmann S, Bohm M \& Nickenig G. Angiotensin AT1 receptor over-expression in hypercholesterolaemia. Annals of Medicine 200032 386-389. (https://doi.org/10.3109/07853890008995944)

23 Wassmann S, Hilgers S, Laufs U, Bohm M \& Nickenig G. Angiotensin II type 1 receptor antagonism improves hypercholesterolemiaassociated endothelial dysfunction. Arteriosclerosis, Thrombosis, and Vascular Biology 200222 1208-1212. (https://doi.org/10.1161/01. ATV.0000022847.38083.B6)

24 Kiliszek M, Maczewski M, Styczynski G, Duda M, Opolski G \& Beresewicz A. Low-density lipoprotein reduction by simvastatin is accompanied by angiotensin II type 1 receptor downregulation, reduced oxidative stress, and improved endothelial function in patients with stable coronary artery disease. Coronary Artery Disease 200718 201-209. (https://doi.org/10.1097/MCA.0b013e32802c7cb0)
25 Urbina EM, Srinivasan SR, Kieltyka RL, Tang R, Bond MG, Chen W $\&$ Berenson GS. Correlates of carotid artery stiffness in young adults: the Bogalusa Heart Study. Atherosclerosis 2004176 157-164. (https:// doi.org/10.1016/j.atherosclerosis.2004.04.023)

26 Brinkley TE, Nicklas BJ, Kanaya AM, Satterfield S, Lakatta EG, Simonsick EM, Sutton-Tyrrell K \& Kritchevsky SB. Plasma oxidized low-density lipoprotein levels and arterial stiffness in older adults: the health, aging, and body composition study. Hypertension 200953 846-852. (https://doi.org/10.1161/HYPERTENSIONAHA.108.127043)

27 Holvoet P, Kritchevsky SB, Tracy RP, Mertens A, Rubin SM, Butler J, Goodpaster B \& Harris TB. The metabolic syndrome, circulating oxidized LDL, and risk of myocardial infarction in well-functioning elderly people in the health, aging, and body composition cohort. Diabetes 200453 1068-1073. (https://doi.org/10.2337/ diabetes.53.4.1068)

28 Zelcer N \& Tontonoz P. Liver X receptors as integrators of metabolic and inflammatory signaling. Journal of Clinical Investigation $2006 \mathbf{1 1 6}$ 607-614. (https://doi.org/10.1172/JCI27883)

29 Keech A, Simes RJ, Barter P, Best J, Scott R, Taskinen MR, Forder P, Pillai A, Davis T, Glasziou P, et al. Effects of long-term fenofibrate therapy on cardiovascular events in 9795 people with type 2 diabetes mellitus (the FIELD study): randomised controlled trial. Lancet 2005366 1849-1861. (https://doi.org/10.1016/S01406736(05)67667-2)

30 Borghi C, Dormi A, Veronesi M, Sangiorgi Z \& Gaddi A. Association between different lipid-lowering treatment strategies and blood pressure control in the Brisighella Heart Study. American Heart Journal 2004148 285-292. (https://doi.org/10.1016/j.ahj.2004.02.003)

31 Strazzullo P, Kerry SM, Barbato A, Versiero M, D’Elia L \& Cappuccio FP. Do statins reduce blood pressure? A meta-analysis of randomized, controlled trials. Hypertension 200749 792-798. (https://doi.org/10.1161/01.HYP.0000259737.43916.42)

32 Borghi C, Prandin MG, Costa FV, Bacchelli S, Degli ED \& Ambrosioni E. Use of statins and blood pressure control in treated hypertensive patients with hypercholesterolemia. Journal of Cardiovascular Pharmacology 200035 549-555. (https://doi. org/10.1097/00005344-200004000-00006)

33 Sposito AC, Mansur AP, Coelho OR, Nicolau JC \& Ramires JA. Additional reduction in blood pressure after cholesterollowering treatment by statins (lovastatin or pravastatin) in hypercholesterolemic patients using angiotensin-converting enzyme inhibitors (enalapril or lisinopril). American Journal of Cardiology 1999 83 1497-1499. (https://doi.org/10.1016/S0002-9149(99)00132-0)

34 Orr JS, Dengo AL, Rivero JM \& Davy KP. Arterial destiffening with atorvastatin in overweight and obese middle-aged and older adults. Hypertension 200954 763-768. (https://doi.org/10.1161/ HYPERTENSIONAHA.109.138248)

Received in final form 19 March 2018

Accepted 6 April 2018

Accepted Preprint published online 6 April 2018 http://www.endocrineconnections.org https://doi.org/10.1530/EC-18-0010
(C)2018 The authors Published by Bioscientifica Ltd

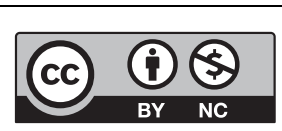

This work is licensed under a Creative Commons Attribution-NonCommercial 4.0 International License. 